\title{
CSN e Volta Redonda: uma relação histórica de dependência e controle
}

Raphael Jonathas da Costa Lima'

\section{Resumo}

A partir da caracterização da morfologia do espaço de Volta Redonda (RJ), o artigo analisa a relação de dependência e controle ocasionada pela presença e atuação da Companhia Siderúrgica Nacional (CSN) neste município. Entende-se que, nas últimas décadas, a Companhia disciplinou o território e restringiu as possibilidades de um desenvolvimento que não passasse pela atividade siderúrgica - até pouco tempo, seu core business. O artigo parte de uma interpretação da matriz socioantropológica do fenômeno company town e sugere que Volta Redonda ainda preserva características fundamentais deste modelo de controle e hierarquia do espaço, em geral identificadas na configuração da sua paisagem urbana. Com isso, procura compreender as implicações decorrentes do desenho monoindustrial e das mudanças técnicas e organizacionais da CSN sobre a geografia econômica do município.

Palavras-chave: Company town. CSN. Geografia econômica. Siderurgia. Volta Redonda.

\section{Introdução²}

Este artigo analisa os impactos das mudanças estratégicas, organizacionais e produtivas da Companhia Siderúrgica Nacional (CSN) sobre Volta Redonda, no sul do estado do Rio de Janeiro, com o objetivo de pensar a conexáo entre as relaçóes sociais do Capitalismo e suas estruturas espaciais a partir da investigação de uma localidade vinculada à atividade siderúrgica. Procurar-se-á verificar se e em que grau a (re)configuraçáo de um landscape $e^{3}$ econômico

1 Doutor em Sociologia e Antropologia pela Universidade Federal do Rio de Janeiro - UFRI (2010) e professor adjunto 2 da Universidade Federal Fluminense - UFF, Niterói, Rio de Janeiro, Brasil. É autor de artigos publicados nas revistas: Caderno CRH (Universidade Federal da Bahia-UFBA), 2012; Revista Pós Ciências Sociais, 2010, entre outras. E-mail: raphaeljonathas@gmail.com.

2 Agradecimento à Fundação Carlos Chagas Filho de Apoio à Pesquisa do Estado do Rio de Janeiro (FAPERJ) através do Edital de Auxilio Instalação (INST)/20/2.

3 A paisagem urbana e industrial construida elou alterada pela intervenção de agentes e empreendimentos econômicos. Utilizar-se-á, ao longo de grande parte do texto, o termo, conforme foi empregado por autores da geografia econômica de matriz anglo-saxônica. 
acarreta mudanças na estrutura social de uma região, e identificar os possíveis efeitos histórico-institucionais deixados pela Companhia sobre a economia regional. Em síntese, ao discutir o processo de reestruturação produtiva da CSN e seus efeitos sobre um dos territórios onde a empresa atua, o artigo visa reforçar a constataçáo feita pelo estudo de Rady (1973) acerca do efeito controlador empreendido pela CSN em distintas regióes do Brasil, notadamente em partes do Médio Paraíba Fluminense. A percepção é que a siderúrgica exerceu um pleno domínio sobre as possibilidades de desenvolvimento regional de áreas nas quais já vinha atuando, nas últimas décadas. A proposta é apresentar evidências que confirmem esta hipótese.

De empresa estatal a "conglomerado" de negócios, a CSN vem orientando seus esforços para a estratégia de adquirir novos negócios e se internacionalizar, o que tem gerado questóes relativas ao lugar ocupado pela atividade siderúrgica, pela Usina Presidente Vargas (UPV) e, consequentemente, por Volta Redonda nesta sua nova configuraçáo produtiva. Por hipótese, acredita-se que a minimização da produçáo siderúrgica esteja conduzindo o município a diversificar sua economia, transformando-se em centro regional de serviços, com reflexos quase imediatos sobre sua cultura construída, desde a década de 1940, ao redor da presença operária, ainda que em obediência a um projeto de "engenharia social" desenhado pelo Estado (HARVEY, 2005). Além disso, o recente deslocamento do foco para Congonhas e Arcos - dois importantes centros de extraçáo de minérios - abre novas possibilidades investigativas e comparativas, sendo interessante buscar indícios que reforcem a condição oligopolista da CSN no sentido de orientar o desenvolvimento e a modernização destas cidades, tal como se acredita ter acontecido em Volta Redonda. $\mathrm{O}$ objetivo é que este texto ajude a estabelecer uma nova frente de estudos sobre uma instituição símbolo da " $2^{a}$ revolução industrial brasileira" ocorrida na primeira metade do século XX, fase em que há a expansão dos investimentos em setores como mineração e metalurgia.

O artigo está estruturado em quatro partes que abordam, respectivamente: 1) os sucessivos processos de aprimoramento técnico da UPV e sua capacidade em determinar os aspectos de uma geografia econômica particular; 2) as características do que se convencionou chamar de company town ${ }^{4}$ e sua matriz

4 Cidade-empresa é a tradução mais utilizada pelos trabalhos produzidos sobre o tema no Brasil. Aqui também se opta por manter o termo original, neste caso apenas por uma questão estilistica. 
socioantropológica; 3) a privatizaçáo, a internacionalização e o programa de diversificação do portfólio da empresa; 4) os traços mais perniciosos do controle e da submissáo de Volta Redonda.

\section{2. $1^{\circ}$ paradigma da dependência: a geografia do distrito hub and spoke (centro-radial)}

Há seis décadas, a CSN vem concentrando o volume de sua atividade siderúrgica no município de Volta Redonda e interferindo na produçâo e reprodução do espaço. Ao longo de todo este período, a Companhia foi responsável pela definiçáo da morfologia do espaço desta antiga company town e se encarregou de orientar as perspectivas de crescimento econômico da cidade, ainda hoje praticamente condicionadas às determinaçóes da empresa, a seus interesses e suas necessidades. Em grande parte, o desenvolvimento da localidade praticamente dependeu dos ciclos de expansáo promovidos pela Companhia desde que iniciou suas operaçóes, em outubro de 1946, com a produção apenas de coque, peças fundidas de ferro-gusa e produtos longos.

O processo de produçáo da CSN é baseado no conceito da siderurgia integrada. Na UPV, o minério de ferro produzido a partir das próprias minas da empresa é beneficiado em máquinas para produzir o sínter, que juntamente com o minério de ferro é fundido com coque e carvão em pó para produzir ferro-gusa, transformado em aço. Nos 30 anos que se seguiram a sua inauguraçáo, a usina passou por sucessivos estágios de expansáo da capacidade de produçáo de aço e laminados, a começar pelo Plano B, delineado em 1947, pouco depois da conclusão do projeto original da usina, o Plano A (MOREIRA, 2000). O Plano B nasceu do reconhecimento da rápida saturaçáo da capacidade máxima de produçáo programada muito em funçáo do acelerado crescimento do mercado consumidor interno de aço. A sua execução foi elaborada durante o governo do presidente Eurico Gaspar Dutra, prevendo entre outros incrementos a construçáo do alto-forno 2 e de 21 fornos na coqueria, a expansáo da capacidade produtiva para 750 mil toneladas/ano de aço e da usina termelétrica de Capivari (SC), de propriedade da Companhia, além da implantaçáo da Fábrica de Estruturas Metálicas (FEM), prevista para 1953 (MOREIRA, 2000).

Moreira (2000) assegura que, antes do término das obras de expansão do novo alto-forno, realizadas entre 1951 e 1955, a diretoria da CSN já 
considerava essas como insuficientes e programava estudos para a execução de outra etapa de ampliaçáo, o Plano C. Estimado em US\$ 30, 5 milhóes, este plano contou com a concessáo de créditos financeiros norte-americanos, com o financiamento de particulares e do governo brasileiro, destinados à compra de equipamentos e ao pagamento de serviços importados. Ele previa, por exemplo, o aumento no número de fornos e na capacidade de produçáo de coque para 1970 toneladas/dia, a ampliaçáo da mineraçáo em sua mina em Casa de Pedra (MG) e a construção de novas casas em Volta Redonda. No entanto, a autora recorda que o Plano C, executado entre 1956 e 1960, nasceu comprometido pela fixaçáo do preço do aço estabelecida pelo Plano de Metas do governo de Juscelino Kubitschek e por conta da nova condiçáo da Companhia, forçada pelo governo a subsidiar o crescimento de outros setores produtivos, a exemplo da indústria automobilística. Embora a produção e o lucro da Companhia estivessem atingindo níveis recordes quando o Plano foi inaugurado em 1961, a CSN progressivamente se viu mergulhando numa longa crise provocada pelas decisóes equivocadas do governo federal e agravada pela combinação entre inflação, redução de investimentos públicos e privados e recessáo no mercado do aço, situação que atingiu o seu auge no início da década de 1990.

Ainda segundo a autora, aos Planos B e C sucedeu-se outro dividido em três etapas de execução e resultado de estudos técnicos feitos desde 1962. Inicialmente prevendo o aumento da capacidade de produçáo de lingotes de aço de 1,4 para 3,5 milhóes de toneladas/ano e com sua implementaçáo negociada desde o governo do presidente Humberto de Alencar Castelo Branco (1964-1967), o chamado Plano D precisou ser revisto por conta da inflaçáo, do controle governamental sobre preços e investimentos e das resistências do governo federal, julgando como desnecessária uma nova expansáo da Companhia enquanto duas outras siderúrgicas estatais, a Cosipa e a Usiminas, trabalhavam com capacidade ociosa de produção.

A expansão apenas foi executada após a reduçáo da capacidade produtiva prevista inicialmente e dividiu-se em três fases, a primeira delas (o Estágio I) iniciada em 1968 com base em projeto desenvolvido pela empresa norte-americana Arthur G. McKee e prevendo atingir a capacidade de produzir 1,7 milhâo de toneladas/ano de lingotes de aço a um custo total estimado em US\$ 115.946 milhóes, sendo US\$ 34 milhóes financiados pelo Eximbank, 
após uma longa negociação com a CSN (MOREIRA, 2000). A obra foi concluída em 1976 e imediatamente seguida pela realização do Estágio II, finalizado em 1978 com o início da construçáo do terceiro alto-forno da usina. $\mathrm{Na}$ ocasiáo, a produção da usina atingiu a marca de 2,4 milhóes de toneladas de aço bruto por ano. Pouco depois, iniciou-se o Estágio III, concluído apenas em 1988, quando a usina foi modernizada a partir da substituição de equipamentos da aciaria e da implantaçấo de mecanismos de controle da poluiçáo. Nessa fase, também se inaugurou o terceiro alto forno e uma fábrica de coque, além de serem feitos os seguintes aprimoramentos: nova instalaçáo de sinterizaçáo, conversor de oxigênio, nova unidade de tiras a quente, nova instalaçáo de laminação a frio, duas máquinas de lingotamento contínuo, duas linhas de galvanizaçáo, uma linha de recozimento para folhas e duas linhas de estanhagem eletrolítica (MOREIRA, 2000).

Todos os estágios de expansão mencionados - em especial, o último deles - atraíram milhares de trabalhadores da construção civil, aumentaram consideravelmente a pressão sobre as ocupaçóes irregulares e a responsabilidade da Prefeitura de Volta Redonda em assegurar a infraestrutura urbana necessária. $\mathrm{Na}$ ocasiáo, o poder público - em consonância com a empresa - elaborou o Plano Estrutural de Desenvolvimento Integrado (PEDI) ${ }^{5}$, confeccionado com a proposta de expandir a capacidade produtiva da CSN de 1,4 milháo de toneladas de aço por ano para 4,5 milhóes de toneladas com base na ampliação da usina para os bairros do Aterrado, Aeroclube, Barreira Cravo, Santo Agostinho e Vila Rica. O PEDI apenas confirmou a dependência do desenvolvimento da cidade em relaçáo à Companhia.

As razóes para este desenvolvimento ter se mantido táo dependente vão além e têm no PEDI apenas um instrumento de reificação. Em primeiro lugar, há uma explicaçáo de ordem geográfica, uma vez que Volta Redonda é uma cidade monoindustrial fundada sob a égide de modelo de grande empresa verticalizada, instituído a partir de um padráo de distrito industrial de tipo hub and spoke (ou Centro-Radial) ${ }^{6}$ (MARKUSEN, 1995), no qual

5 Lei Municipal no 1411, Câmara Municipal de Volta Redonda, $1^{\circ}$ de fevereiro de 1977.

6 Para construir a tipificação dos distritos industriais, Markusen entrevistou representantes de empresas, associações patronais e sindicatos, além de especialistas em economia regional. A configuração dos distritos estipulada pela autora considera aspectos como a distribuição das firmas por tamanho, o padrão de relações industriais, o grau de desintegração vertical, as transações entre as firmas de um mesmo distrito, a capacidade 
predomina a plena submissão do território à lógica da empresa. Não apenas em Volta Redonda, mas em todo o conjunto da regiáo do Médio Paraíba Fluminense, a condiçâo oligopolista alcançada pela CSN como firma-chave organizou a estrutura industrial e ditou o dinamismo da economia regional, nas últimas décadas. A Companhia configurou um distrito industrial hub and spoke porque, ao se posicionar como unidade industrial mais relevante da regiâo, subordinou outros negócios locais, o mercado de trabalho e as pequenas firmas ao seu próprio padrão produtivo (MARKUSEN, 1995) ${ }^{7}$. Esta é uma constataçáo que já está presente em trabalhos pioneiros produzidos sobre a trajetória da Companhia, a começar pela reflexão de Rady (1973), na qual é destacada a atuaçáo da empresa na atraçáo e no desenvolvimento de indústrias e negócios que variavam de pequenas e grandes firmas - que utilizavam aço e produtos químicos produzidos pela usina como insumos - aos bancos e lojas de departamento, cuja expansão atendia à crescente demanda de uma comunidade siderúrgica em expansão.

Na realidade, conforme assegura Morel (1989), desde 1952 já se desenvolvia uma malha industrial atraída pela chegada da usina e composta pelas seguintes empresas: Companhia Estanífera do Brasil, Forjas Nacionais S.A., Companhia de Cimento Vale do Paraíba, White Martins S.A., etc. (MOREL, 1989, p. 243). Ainda segundo a autora, alguns anos após a emancipação do município, fazendeiros, comerciantes e empresários locais constituíram a Associação Comercial, Industrial e Agropastoril (ACIAP-VR), espelhando a complexidade e a diferenciação dos interesses da comunidade. Esta e outras associaçôes locais surgidas no período tinham maneiras específicas de intervir na comunidade, mas não se opunham aos interesses da empresa e estavam decididas a explorar o aporte institucional da Companhia. Utilizaram-se desta condiçáo inúmeras vezes para alavancar a construção de distritos industriais em Volta Redonda ${ }^{8}$. Ademais, os estágios de expansão

de inovação, as instituições de coordenação de âmbito distrital e a organização da produção (MARKUSEN, 1995, p. 13).

7 A analogia é com o eixo central e os raios de uma roda: uma unidade econômica mais importante (o eixo) em cujo entorno se congregam outros negócios a ela relacionados (MARKUSEN, 1995, p. 21).

8 A incubação de empresas contribuiu decisivamente para a ampliação do mercado de trabalho local e regional a partir da formação de perfis de operários: de um lado os operários "estratégicos", contratados com salários mais altos, melhores perspectivas de progressão e melhores condições de trabalho; de outro, os operários "periféricos", empregados pelas subcontratadas, com baixos salários e condições de trabalho inferiores (MANGABEIRA, 1993, p. 70-7I). 
favoreceram a incubação de novas empresas e, ao menos desde 1975, diversas, em sua maioria de pequeno e médio porte, surgiram interessadas nos serviços necessários à expansáo e na oferta de eixos, cilindros e outras peças de manutenção para a usina.

\section{3. $2^{\circ}$ paradigma da dependência: os aspectos morfológicos ${ }^{9}$ de uma company town}

Para a formação de Volta Redonda, o Estado brasileiro inspirou-se no princípio da "engenharia espacial" ou manipulação deliberada do landscape, empregado por propostas de engenharia social que orientaram a construçáo de diversas cidades industriais europeias e norte-americanas. Da França, por exemplo, a CSN incorporou elementos da patronagem desempenhada pela indústria siderúrgica na regiáo da Lorena, no final do século XIX, e caracterizada pela transposiçáo de relaçóes típicas do campo para o mundo industrial ao passo que procurava assegurar concessóes às demandas e tradiçóes dos trabalhadores. E dos Estados Unidos houve a apropriaçáo do "paternalismo industrial" designado por um tipo de relaçáo de trabalho que recorreu a elementos da estratégia patronal para recrutar, fixar, estabilizar e controlar os trabalhadores qualificados daquele país, com a concessão de programas de benefícios sociais, como assistência médica, educacional, recreativa e a construçáo de moradias ${ }^{10}$, propostas típicas da indústria siderúrgica norte-americana do início do século XX (MOREL, 1989). A ideia da "família siderúrgica" preconizada pelos estudos sobre Volta Redonda/CSN remete ao entendimento da formaçáo da cidade como resultante de um processo híbrido, envolvendo controle e tutela como alicerces de comprometimento com um projeto econômico, político, ideológico e estratégico de ordem nacional com impactos locais.

A cultura desta cidade operária construiu-se impregnada pelas atividades da Companhia, a qual constituiu uma agenda política comprometida com suas expectativas e demandas, e testemunhou o nascimento de uma

9 A caracterização da organização do espaço fundamentada na existência de estruturas e relações sociais sedimentadas e historicamente reproduzidas.

10 A análise feita por Morel acerca da construção de bairros e moradias operárias em Volta Redonda pode ser interpretada como altamente influenciada pela reconstrução de Engels (2010) da configuração urbana de cidades industriais inglesas, notadamente Manchester, onde a indústria britânica teve seu ponto de partida e seu centro. 
vigorosa competição entre capital e trabalho (MARKUSEN, 1995). Classificar-se-á esta ordem segundo um espectro socioantropológico, que se acredita ter se mantido preservado a despeito das mudanças impingidas pela passagem da CSN de empresa pública para "privatizada", a partir de 1993.

Esta morfologia de company town instituiu um conjunto de limitaçóes estruturais, uma vez que, através de sua relaçáo inexoravelmente visceral com a usina, Volta Redonda testemunhou o surgimento de um arranjo sociopolítico polarizado (LOCKE, 1995) típico de cidades monoindustriais onde predomina o poder de uma grande empresa sobre a política local e a ação dos sindicatos. Por décadas a fio sem sofrer uma significativa oposiçáo do governo local e de outros grupos de interesse e partidos políticos, a CSN conseguiu moldar a indústria e o mercado de trabalho da cidade segundo uma estrutura piramidal altamente integrada, cultivando uma visão extremamente hierárquica e autoritária do seu papel e exercendo uma combinação de repressáo e paternalismo sobre o principal sindicato local (LOCKE, 1995, p. 127), ${ }^{11}$ entidade por muitos anos tutelada ${ }^{12}$ (MONTEIRO, 1995).

A Companhia, segundo Morel (1989), é uma siderúrgica singular pela capacidade demonstrada em construir uma cidade, podendo modelá-la praticamente do zero de forma a estratificá-la, atribuindo divisóes e funçóes espaciais específicas. Esta receita não foi repetida por outras estatais do período, como a Vale do Rio Doce, a qual encontrou em Itabira (MG) uma cidade já constituída e economicamente decadente, tendo condiçóes apenas de redefinir sua estrutura urbana e social (MOREL, 1995). Obviamente, a CSN estratificou um espaço que já náo era exatamente "liso", mas foi capaz de impor novas "rugosidades" à estrutura e aos processos sociais já instituídos

II A leitura de Locke é estrutural, mas reconhece que, apesar da influência dos legados históricos de desenvolvimento político e econômico que caracterizam os variados contextos subnacionais, existe uma possibilidade de recombinação de uma ordem econômica qualquer a partir, por exemplo, de conflitos políticos periódicos entre os atores econômicos locais. Por isso, ele aplica a metáfora da "colcha de retalhos" para caracterizar a recombinação de fragmentos de "velhos tecidos" para promover a construção de um novo arranjo

120 ano de 1984 oficialmente demarca a "insurreição" do movimento sindical de cunho combativo na cidade, materializado na perspectiva classista da Central única dos Trabalhadores (CUT). Contudo, alguns autores, como Bedê (2007) e, posteriormente. Graciolli (2009), vêm questionando a tese segundo a qual o movimento sindical de Volta Redonda foi pouco atuante em fases anteriores aos anos 1980. Os autores argumentam que há indícios de que, em anos anteriores, ocorreram mobilizações com grau considerável de repercussão. Dois exemplos seriam a greve de trabalhadores da construção civil (ligada à CSN), na década de 1950, e uma greve de resistência ao Golpe Militar, em $1^{\circ}$ de abril de 1964. 
pela produção cafeeira em vigor na regiāo (SANTOS apud LOPES, 2003). A regiáo atravessou um momentâneo ciclo de prosperidade encerrado pela decadência da monocultura agrícola, após ter sido o centro da produçáo nacional de café (especificamente, entre 1850 e 1900), mas se reergueu ao ponto de se constituir no maior centro de transformaçáo da estrutura econômica do país (BASTOS, 1957). A empresa foi a protagonista deste processo de soerguimento, aperfeiçoou o arcabouço estrutural regional e passou a subordinar as perspectivas de autonomização da matriz econômica de parte considerável da regiáo do Médio Paraíba Fluminense às suas próprias visóes, determinaçóes e flutuaçóes. Em outros termos, a CSN trabalhou com a estratégia de instituir uma espécie de aparato político-ideológico da produção, necessário, por exemplo, para regular as relaçóes de produçáo (BURAWOY apud DINIUS, 2011).

A Companhia Siderúrgica Nacional (CSN), pelas palavras de Rady (1973), é uma "instituição industrial" por toda a sua capacidade em absorver tecnologia e recursos estrangeiros, assim como em incorporar padróes culturais e políticos nacionais à sua forma de gestáo e de relaçáo com o território (incluindo comunidades, poder público e outros agentes econômicos). É também uma "instituição total" (GOFFMAN apud MOREL, 1989) pela forma como promoveu o "desnudamento" 13 (LEITE LOPES, 1988) e a ruptura entre sua primeira geração de operários da usina e a trajetória pessoal anterior de cada um deles, reeducou moralmente esses trabalhadores e formulou um princípio de cidade inspirado na perspectiva da higienizaçáo (MOREL, 1989, p. 98). Estas duas definiçóes reforçam a hipótese segundo a qual a Companhia agiu, ao longo das últimas décadas, impondo um conjunto de limitaçóes estruturais capazes de interferir na configuraçáo política, econômica e cultural de um território.

Inspirada no princípio do panoptismo, a CSN introduziu um arranjo de gestão através do encaixamento espacial da vigilância hierarquizada, contínua e funcional. No desenho do Panóptico o poder náo é organizado em funçáo

13 Na literatura sobre as "instituições totais" de Goffman (1974), o "desnudamento" é criado por efeito da domesticação do internato novato. Na descrição de Leite Lopes (1988), ela antecede a prática do aliciamento da mão de obra exercida pelos agentes da Companhia de Tecidos Paulista (CTP). O "desnudamento" demarca a "separação dos grupos de trabalhadores aliciados vis-à-vis de seus bens, de suas coisas, de sua concepção de tempo, de suas condições usuais de produção e de reprodução social [...]” (LEITE LOPES, 1988, p. 45). 
de si, mas para tornar mais fortes as forças sociais - aumento da produção, desenvolvimento da economia, difusão da instruçáo e elevaçáo do nível da moral pública (FOUCAULT, 1997). Este processo tem se mantido intacto, a despeito de Volta Redonda oficialmente abandonar a condiçáo de company town, na transiçáo dos anos 1960 para os 1970. A CSN, assim como as demais empresas públicas brasileiras - especialmente aquelas do setor produtivo -, passou a ser regida por critérios de eficiência idênticos aos do setor privado, organizando-se sob a forma de conglomerados, maximizando lucros e exercendo atividades internacionais" (PIQUET, 1998, p. 73-74). Mudanças que - complementando o argumento de Piquet (1998) - foram entendidas como necessárias para garantir a viabilidade de uma Companhia que despendia muitos recursos para garantir a reproduçáo desta força de trabalho à medida que obtinha enormes prejuízos com a pouca competitividade no mercado siderúrgico. Enquanto isso, o autoritarismo da Companhia foi incidindo sobre associaçóes empresariais e sindicatos, dificultando a construção de parcerias e coalizóes pró-desenvolvimento aptas a orientar a elaboração de um novo arranjo institucional capaz de deslocar a siderúrgica da condiçáo de agente econômico, simbólico e político central.

\section{A holding CSN: da siderurgia à mineração}

O elevado número de empregos e a extensão da sua política de bem-estar social são dados que ajudam a realçar o controle da Companhia. Em 1989, quando iniciou um rigoroso programa de saneamento da usina (LIMA NETTO, 1993), a CSN gerava em torno de 25 mil empregos diretos em Volta Redonda, e administrava um complexo sistema de bem-estar social que incluía escolas, clubes e até um hospital para funcionários e seus familiares, ativos incluídos no leiláo de privatizaçáo realizado em abril de 1993, na Bolsa de Valores do Rio de Janeiro - BVRJ.

No momento em que passo a direção da CSN aos novos controladores, sinto-me tranquilo. Ao longo dos 29 anos em que me dediquei ao serviço na empresa, estive muito envolvido com ela. A CSN, para mim, é assim como uma filha às portas do altar. Assim, como um pai, ao casar sua filha, se preocupa com o seu futuro, eu também tinha os meus cuidados com essa filha tão querida que é a CSN. Agora, no entanto, ao conhecer o genro, personificado na figura dos novos controladores, passo a ser apenas aquele pai tranquilo e feliz, que augura para sua filha um futuro dos mais brilhantes. (EX-PRESIDENTE da CSN, 20II). 
Mediante o retrato configurado pela privatização, acompanhado de uma internacionalizaçáo com altos e baixos, a dinâmica do mercado de trabalho de Volta Redonda foi negativamente impactada nos últimos anos, verificando-se a reduçâo no número de empregos formais, algo favorecido pela séria reestruturação da usina e pelo transbordamento do processo geral de reestruturaçáo para outros setores (DULCI, 2008). Estima-se que mais de oito mil funcionários tenham sido desligados apenas entre 1990 e 1997 por programas de enxugamento, como o Plano de Demissão Incentivada (PDI), acertado com a direçáo do Sindicato dos Metalúrgicos para demitir 900 funcionários (10\% do total) alocados nas unidades de Volta Redonda e Casa de Pedra. E calcula-se que, apenas em 1997, essa redução, especificamente em Volta Redonda, tenha sido na ordem de $13 \%$, permanecendo a geraçáo de empregos formais na cidade praticamente estagnada até 2004. Para completar este cenário, o percentual de trabalhadores na indústria local caiu de $37 \%$ para $20,6 \%$, entre 1996 e 2006, havendo também uma redução de $20 \%$ no rendimento dos trabalhadores (DULCI, 2008).

Associado a este panorama de aparente desindustrializaçáo ${ }^{14}$ (COWIE; HEATHCOTT, 2003), números fornecidos pelo Sindicato dos Engenheiros de Volta Redonda (SENGE-VR) sugerem que, desde 2003, a Usina Presidente Vargas (UPV) vem empregando em média 8 mil funcionários diretos, dos quais 550 sáo engenheiros. A volatilidade da atividade siderúrgica em função das instabilidades do mercado internacional gera ondas frequentes de demissáo na usina, sempre com grande repercussáo no conjunto da sua comunidade siderúrgica. Em 1983, por exemplo, dificuldades enfrentadas pela Companhia e agravadas por uma crise mundial do aço provocaram a demissáo de $5 \mathrm{mil}$ funcionários, causando efeitos irradiadores sobre o conjunto de pequenas e médias indústrias fornecedoras de eixos, cilindros e outras peças de manutençáo para a usina. Influenciadas pela retraçâo na demanda dos produtos siderúrgicos, estas empresas demitiram, contribuindo para elevar para 8 mil o número de operários desempregados (em um total estimado de $40 \mathrm{mil}$ ), em Volta Redonda (O GLOBO, 1983). Episódio recente de demissóes ocorreu

14 Apesar de o corte de empregos ser um aspecto central na desindustrialização (e na globalização) é de extrema importância considerar os efeitos que ela provoca em termos de relações espaciais, política local, organização do trabalho, modificações na paisagem urbana, os impactos que acarreta para as comunidades afetadas, $O$ legado ambiental e as mudanças na identidade (COWIE; HEATHCOTT, 2003). 
entre dezembro de 2008 e janeiro de 2009 com o desligamento de 1.200 funcionários da usina em virtude da forte crise econômica mundial. Desta vez, as demissóes tiveram enorme repercussáo, obrigando o Sindicato dos Metalúrgicos e a Igreja Católica a se articularem e criarem o movimento "Demissáo Zero: o trabalhador náo vai pagar pela crise”, pela readmissão dos demitidos (LIMA, 2010a; RAMALHO, 2012).

A privatizaçáo teve reflexos danosos sobre Volta Redonda e que vão além do desemprego provocado pelas demissóes. Uma síntese dos acontecimentos do pós-privatização pode ser encontrada na tese de doutorado (LIMA, 2010a), a qual aponta que o processo náo foi acompanhado por programas que buscassem reorientar a cidade em termos de uma nova vocaçáo econômica. Ademais, a empresa nunca empreendeu iniciativas que visassem ao desenvolvimento econômico local, nem políticas e programas de requalificação de mão de obra e de revitalizaçáo dos espaços urbano e industrial. Mesmo programas pró-sustentabilidade, de criação de espaços verdes e de modernização, que reafirmassem minimamente o seu compromisso com a localidade, nunca foram empreendidos, ao contrário do que se passou ou tem se passado em company towns igualmente emblemáticas, como Saint-Etienne (França), com a Michelin, ou Wolfsburg (Alemanha), com a Volkswagen, conforme demonstram algumas análises recentes (RAMALHO, 2010; VÉDRINE, 2011).

Após a privatização, o Grupo Vicunha, detentor do maior percentual das açóes da nova Companhia, iniciou uma profunda racionalizaçáo da gestáo com a criaçáo de um Centro Corporativo, uma espécie de holding da empresa, responsável pelas áreas de siderurgia, energia e logística. A CSN, entáo, iniciou um arrojado programa de expansão, minimizando a condiçáo estratégica da Usina Presidente Vargas e, por conseguinte, de todo seu complexo localizado em Volta Redonda. Adquiriu participaçóes em empresas de energia, como a Light, ferrovias e portos, e liderou o Consórcio Brasil, o qual adquiriu o equivalente a $27 \%$ do capital total da Companhia Vale do Rio Doce (CVRD), após a sua desestatizaçáo. Vale frisar que, com a privatizaçáo, o grupo de acionistas já havia assumido um conjunto de ativos na cidade - a Usina Presidente Vargas (UPV), a Escola Técnica Pandiá Calógeras, os clubes, o hospital siderúrgico e inúmeros terrenos subutilizados - e em outras regióes, como Congonhas (MG), onde a mina de Casa de Pedra se converteu em um dos seus ativos mais importantes. 
As açóes empreendidas partiram de um planejamento estratégico elaborado pela Mckinsey, empresa de consultoria norte-americana. Concluído em 1997, o planejamento previa a implantaçáo de uma mentalidade de unidades de negócios, de custos e de gerenciamento em contrapartida à mentalidade industrial. Além disso, atestava que a Companhia apresentava os menores custos de produçáo de aço do mundo, beneficiando-se de energia, máo de obra e insumos baratos, apenas comparados às usinas siderúrgicas coreanas. É possível afirmar que, em termos qualitativos, o trabalho foi mais significativo para as mudanças de rumo da Companhia do que a própria privatizaçáo. Se, por um lado, com a privatizaçáo transformou-se um cenário deficitário (um prejuízo acumulado de 5 bilhôes de dólares entre 1979 e 1992) em favorável (lucro de 1,7 bilhão de dólares entre 1993 e 2001), foi através desse planejamento elaborado pela Mckinsey que a logística foi identificada como o ponto mais vulnerável e, por sua vez, estratégico da Companhia.

A reorganização administrativa da empresa envolveu a aplicação de noçóes de gerenciamento financeiro, contábil, de relaçóes com o mercado, suprimentos, logística, etc., além de implantar uma metodologia de decisóes mais colegiadas atrelada a um Centro Corporativo criado pela direçáo da Companhia. O Centro passou a deter o controle de todas as atividades náo ligadas à produçáo, como finanças, controladoria, recursos humanos, relaçóes com o mercado, auditoria, Fundaçáo CSN e os fundos de pensão, já sinalizando também a intenção de vender alguns dos patrimônios da empresa, como o hospital da CSN e a escola Macedo Soares, símbolos do modelo de bem-estar social implantado pelo governo brasileiro, na década de 1940. Desta forma, unidades estratégicas como a Fábrica de Estruturas Metálicas (FEM) - subsidiária da CSN que empregava quase 6 mil pessoas apenas em Volta Redonda, além de possuir unidades em Sáo Luís do Maranháo e em Paranaguá (PR) - se fundiu à Montreal (uma de suas prestadoras de serviços) e, logo depois, teve sua venda financiada pelo BNDES para a Sade Vigesa, controlada pelo grupo Indústrias Elétricas do Paraná LTDA. (INEPAR) (DIAS, 2010).

Em seguida, a empresa adotou um intenso programa de atualização tecnológica de forma a aumentar a eficiência do processo produtivo com a ampliaçáo da capacidade de produçáo para cerca de 5,6 milhóes de toneladas de aço bruto por ano. A siderúrgica também passou a diversificar sua atuaçáo, constituindo junto com o grupo alemáo ThyssenKrupp uma joint venture para 
a instalação da GalvaSud (unidade de fabricação de aços galvanizados, em Porto Real), fortalecendo o segmento de cimentos, ampliando as operaçóes de mineraçáo e investindo em logística com a construçáo da ferrovia Transnordestina, que ligará o Porto de Pecém, no Ceará, ao Porto de Suape, em Pernambuco. Também se tornou uma das siderúrgicas mais eficientes do mundo com uma margem operacional de 45\% (líder global Arcelor-Mittal registra algo em torno de 20\%) e tendo o seu valor de mercado aumentado de 18 para 40 bilhōes de dólares entre 2002 e 2010 . Ao mesmo tempo, tem investido na sua internacionalizaçáo a partir da aquisição da Heartland Steel (hoje CSN LLC), usina para laminaçáo localizada em Terre Haute, no estado americano de Indiana, e da Lusosider Aços Planos, S.A., em Portugal. A Lusosider é a única indústria portuguesa do setor siderúrgico a produzir aços planos com revestimento anticorrosáo e dispóe de uma capacidade de produçáo de 550 mil toneladas/ano de produtos planos.

Ao tentar fortalecer seu portfólio e diversificar suas atividades, a CSN trabalha, sobretudo, com a meta de se tornar a quarta maior mineradora do mundo em 2015, com uma produçáo estimada em 100 milhóes de toneladas de minério de ferro nas suas minas, deixando a siderurgia em segundo plano. Destarte, Volta Redonda vem rapidamente perdendo espaço para Congonhas e Arcos (MG) como principal locus de atuaçáo da Companhia. Muito possivelmente, o reconhecimento da condiçáo estratégica dessas minas de onde se extrai minério de ferro, calcário e dolomita de baixo custo tenha acompanhado a recuperaçáo do setor logístico da Companhia a partir da melhoria das ferrovias e do investimento nos terminais de carvão e de contêineres do Porto de Sepetiba, no Rio de Janeiro (Sepetiba TECON) ${ }^{15}$. Além disso, é na região de Congonhas e Arcos que a Companhia vem sinalizando com a possibilidade de erguer duas novas usinas de aços longos e duas pelotizadoras para a compressáo do minério de ferro.

\section{Hierarquia e autoridade: disciplinando o território}

Há décadas, a CSN atravessa sucessivos processos de modernização - quase sempre dificultados pela falta de recursos financeiros - e de racionalizaçáo da produção na UPV. Mangabeira (1993) é enfática ao indicar que o Plano

15 O BRILHO do aço. Revista Exame, II jul. 2001. 
D - iniciado em 1962 -, além da mencionada modernização tecnológica, incluiu alteraçóes na composição da força de trabalho e a racionalizaçáo do sistema administrativo da Companhia. Embora a década de 1960 sinalize o crescente estímulo da Companhia ao trabalho de novos agentes como forma de minimizar o peso do seu paternalismo (DINIUS, 2011), náo é possível afirmar que isso delimite o pleno rompimento com o arranjo panóptico alicerçado no modelo company town. O panoptismo, conforme a interpretaçáo de Foucault (1997), não demarca a soberania, mas a disciplina instituída pela combinaçáo entre as esferas militar, pedagógica e produtiva, correspondendo à exata configuração apresentada pelo município entre 1977 e 1985, quando foi considerado área de segurança nacional pelo governo federal. Durante essa fase, os três prefeitos ${ }^{16}$ indicados que administraram Volta Redonda tinham trajetórias profissionais caracterizadas seja pela atividade docente, seja pela militar ou pela atuaçáo em cargos de gestáo na Companhia.

Náo é exagero afirmar que Volta Redonda náo deixou de ser uma company town e que a CSN nunca abandonou sua perspectiva de dominaçáo pela disciplina, pelo simples fato de instituir uma geografia absolutamente dependente da lógica de produção e da hierarquia (MINAYO, 2004). A company town é reflexo de uma geografia econômica permeada por relaçóes (sociais) capitalistas, onde a forma física do landscape se constrói por efeito dos conflitos entre diferentes atores sociais, alguns dos quais com maior poder de impor e oficializar sua referida visão (legítima) do mundo social (BOURDIEU, 2001; HEROD, 2011). Neste processo, o espaço social destoa do espaço geográfico por definir posiçóes relativas ocupadas por agentes e grupos de agentes conforme a distribuiçáo de poder e de capital ${ }^{17}$. Por ser construído na base

16 Georges Leonardos (de fevereiro de 1977 a abril de 1979) - Engenheiro, ex-presidente da Companhia Brasileira de Projetos Industriais (COBRAPI) e ex-diretor do Centro de Pesquisas da CSN: Aluízio de Campos Costa (de abril de 1979 a abril de 1982) - Coronel da Academia Militar das Agulhas Negras (AMAN), administrador executivo do Hospital da CSN (1975/1976) e vice-presidente de serviços da CSN (1976/1978); Benevenuto dos Santos Neto (de abril de 1982 a dezembro de 1986) - Professor universitário e ex-diretor administrativo e financeiro da COBRAPI (EGALON, 2002).

17 Segundo Bourdieu (200I), o espaço social é construído com base na ocorrência de diferentes espécies de poder e de capital nos diferentes campos em que os agentes atuam. "Falar de um espaço social é dizer que não se pode juntar uma pessoa qualquer com outra pessoa qualquer, descurando as diferenças fundamentais, sobretudo econômicas e culturais" (BOURDIEU, 200 I, p. 138). O espaço geográfico e o social nunca coincidem completamente e muitas diferenças associadas ao efeito do espaço geográfico, como a oposição entre centro e periferia, são o efeito da distância no espaço social, quer dizer, resultam da distribuição desigual das diferentes espécies de capital no espaço geográfico (BOURDIEU, 200I). 
da distribuição do capital, o espaço social é sempre hierarquizado e os reagrupamentos na sua estrutura "apresentam maiores probabilidades de serem estáveis e duradouros enquanto as outras formas de reagrupamento estaráo sempre ameaçadas pelas cisóes e oposiçóes ligadas às distâncias no seu interior" (BOURDIEU, 2001, p. 137). Tal afirmaçáo sugere, portanto, que a posição ocupada pela Companhia nesse espaço social assegurou a atualizaçáo da sua soberania e da sua autoridade sobre o referido território, desaguando no estabelecimento de um contencioso territorial entre empresa e município, com enormes prejuízos para este último, especialmente em termos ambientais, fiscais e territoriais.

Há um caso emblemático do contencioso territorial entre o município e a CSN: é o prédio que abrigou a antiga sede da empresa em Volta Redonda. Com 16 andares, o edifício, no bairro Santa Cecília, em frente à passagem superior da Usina Presidente Vargas, está subutilizado. A Prefeitura e o Estado chegaram a fazer à CSN uma proposta de compra do prédio para transformá-lo em universidade ou centro comercial, mas as negociações não evoluíram. Renato Soares Ramos, presidente do Sindicato dos Metalúrgicos de Volta Redonda, diz que o prédio tornou-se um "elefante branco". Chegou a receber mais de três mil funcionários da área administrativa, mas hoje abriga menos de 100, segundo um boletim produzido pelo sindicato. (VALOR ECONÔMICO, 2013).

Conforme sugere Harvey (2005), o Capitalismo se movimenta de acordo com uma dinâmica muito peculiar de acumulaçáo e localizaçáo, na qual está presente a tensão entre preservar os investimentos passados na construção do ambiente, e destruir esses investimentos para abrir novos espaços para a acumulaçáo (HARVEY, 2005, p. 52). Com base neste entendimento, é fundamental que o debate pós-reestruturaçáo incida sobre a forma como a Companhia se (re)apropria e disciplina os territórios onde ela historicamente se enraizou, tornando limitadas as possibilidades de um desenvolvimento regional que náo passe por ligaçóes diretas e indiretas com o seu core business ${ }^{18}$. $\mathrm{Na}$ associação entre a teoria da acumulaçáo e entendimento da estrutura espacial concebida pelo autor, significa interpretar ativos a exemplo da Usina Presidente Vargas (UPV) como capitais fixos e imobilizados, e a paisagem geográfica constituída em seu entorno como lugar de contradição e tensáo, e náo como expressão do equilíbrio harmonioso (HARVEY, 2005, p. 53). As espacialidades

18 Atividade forte ou central da empresa. 
do presente estão em contato permanente com as do passado e, assim, o landscape integrado por Volta Redonda e seu entorno parece condenado a refletir permanentemente condiçóes específicas de acumulaçáo que ossificaram um conjunto de relaçóes sociais (conflituosas) instituídas no momento de sua implantação (HEROD, 2011).

Às diversas açôes disruptivas (corte no programa oficial de habitaçáo; reestruturaçáo com o enxugamento de funcionários e a implantaçáo de processos modernos, entre o final dos anos 1980 e o início dos anos 1990; a privatizaçáo enquanto fato social; o abandono da condição de empresa nacional símbolo pela internacionalizaçáo e a adoção de um formato de holding com diversos braços de atuaçáo) não se seguiu uma ruptura com a dominação da Companhia. Se, por um lado, a configuração da "Nova Companhia" contribui significativamente para derrubar o mito da plena associação entre Companhia e cidade - seguramente, um dos mais replicados pela literatura dedicada ao par CSN/Volta Redonda -, por outro não se traduz em ação disruptiva por parte de um território que ainda vive sob a expectativa de novas atualizaçóes na usina, capazes de gerar emprego, atraindo desenvolvimento e progresso. Eventos recentes, como o aguardado anúncio da construçáo do alto-forno 4, ao gerar fortes expectativas em Volta Redonda, ajudam a confirmar esta hipótese, dando indícios de que na cidade nunca se cogitou a ruptura completa com sua monoindústria, a despeito de todos os efeitos (negativos) que a atividade siderúrgica gera em termos de meio ambiente, concentração do espaço e do desemprego por conta da volatilidade do preço do aço no mercado internacional.

O ponto final no último capítulo para o fim da novela da instalação do alto-forno 4 da CSN em Volta Redonda caberá à Assembleia Legislativa do estado. Na semana passada, depois de meses de negociação, a CSN e o governo do estado chegaram a um consenso para que o investimento seja realizado na cidade. A mensagem da governadora Rosinha Garotinho concedendo incentivos fiscais para o empreendimento será encaminhada à ALERJ 19 nesta terça-feira, dia 16. Serão R \$2,4 bilhões de investimentos, dos quais R\$1,6 bilhão da Companhia e o restante de empresas contratadas. As estimativas são de que a etapa civil da obra proporcione até 10 mil empregos e que a CSN venha a contratar pelo menos 600 novos trabalhadores para a nova unidade. O prefeito (Antonio Francisco) Neto disse ter recebido da CSN a informação de que também serão instalados na Usina Presidente Vargas a Bateria

19 Assembleia Legislativa do Estado do Rio de Janeiro. 
de Coqueria I e III, Sinterização de Minério de Ferro V, Aciaria II e Lingotamento Contínuo de Placas V. - Alto-forno agora só depende de deputados. (FOCO REGIONAL, 200320).

Portanto, o espaço de relaçóes (BOURDIEU, 2001) implantado em Volta Redonda náo se modificou após a privatizaçáo, aliás, não se modificou por conta da privatizaçáo. A venda da Companhia e de todos os seus ativos na cidade (usina, terras, clubes, escolas e hospital) apenas explicitou uma condiçáo de dominação que tem na concentração fundiária o seu traço mais perverso e que vem asfixiando o poder público em sua busca por novas possibilidades de desenvolvimento para o município.

Além de não ter autonomia, Volta Redonda precisa acompanhar a expansão da CSN para Arcos/Congonhas; Estados Unidos e Europa por circunstâncias da sua intencionalidade em se tornar um global player ${ }^{21}$ da produção de aço e da exportação de commodities. Aqui se impóe uma breve comparaçáo com o percurso adotado pela Companhia Vale do Rio Doce (CVRD) na composição da "geografia da mina" (MINAYO, 2004), em Itabira.

De sua fundação até a privatizaçáo em 1997, a CVRD teve uma trajetória muito parecida com a da CSN, com algumas particularidades, como o fato de já encontrar no momento da sua instalaçáo uma cidade constituída; e estrategicamente se modernizar na transição dos anos 1970 para os anos 1980, por ocasiáo da forte competiçáo no mercado internacional de minérios, em vigor já naquele período. A CVRD induziu uma açấo disruptiva no território de Itabira, formulando uma estrutura social mais afinada com suas especificidades de mineradora estatal; assistiu um processo de "ruptura da dominação" (MINAYO, 2004), nos anos 1980, momento em que viu se constituir uma sociedade civil atuante e contrária à açáo predatória da mineração; e testemunhou o surgimento de uma aliança entre poder público e empresariado, insatisfeitos com a dominação histórica da Companhia e com a baixa diversidade produtiva da cidade ${ }^{22}$.

20 Segundo um representante da CSN, a construção do alto-forno acabou não se concretizando porque retrações no mercado internacional do aço inviabilizarem o negócio. Fonte: REPRESENTANTE da CSN. Entrevista: 10 ago. 2012.

21 Termo empregado para classificar agentes econômicos relevantes na cena global contemporânea.

22 A Associação Comercial (ACITA), a Prefeitura e os movimentos sociais juntaram-se para elaborar o projeto "Itabira 2025", visando impulsionar quatro áreas da economia local: indústria, agropecuária, comércio e turismo. E, em 1989, foi criada a Agência de Desenvolvimento de Itabira (ADI) (MINAYO, 2004). 
Por sua vez, a CSN se empenhou em limitar possibilidades emancipatórias, muitas vezes utilizando-se do poder público como instrumento de controle social. $\mathrm{O}$ anteriormente citado Plano Estrutural de Desenvolvimento Integrado (PEDI) funcionou como uma instrumentalizaçáo legal de organizaçáo e hierarquização do espaço físico do município, durante a gestão do engenheiro Georges Leonardos. Em certo sentido, o PEDI compunha um conjunto de esforços - que incluía também a construçấo de conjuntos habitacionais -, visando frear o aumento no número de ocupaçóes irregulares, ensaios de subversão do espaço capitaneados por um movimento de posseiros urbanos surgido na esteira dos estágios II e III do Plano D de expansáo da usina, os quais atraíram dezenas de milhares de trabalhadores da construção de civil (SOUZA, 1992; LIMA, 2010a). Assim sendo, seguindo a classificaçáo de distrito industrial de tipo hub and spoke sugerida por Markusen (1995), Volta Redonda viu-se dependente de sua indústria mais importante para atrair investimentos e sua administraçáo municipal funcionou, durante anos, como agente de cumprimento da agenda e dos interesses dessa "instituição industrial". Com um movimento sindical enfraquecido ${ }^{23}$ pela privatização, uma classe empresarial opaca e incapaz de formular para si novas dinâmicas associativas e produtivas, os números indicam que, a despeito de se manter como o maior PIB regional, Volta Redonda caiu para a quinta colocaçáo em termos de valor adicionado à indústria ${ }^{24}$. Por fim, apesar de estar construindo uma fábrica de aços longos em suas instalaçóes na UPV, com a possibilidade de gerar cerca de mil empregos (entre diretos e indiretos), o deslocamento do foco para a mineraçáo tem constituído um cenário pessimista para o futuro do município.

\section{Considerações finais}

Este artigo procurou problematizar alguns aspectos relacionados ao desenvolvimento do município de Volta Redonda a partir da imbricaçáo da CSN em seu território. Entende-se que esta problematizaçáo seja pertinente nâo pela perspectiva aqui assumida de reafirmar que o crescimento do município margeou todo o processo de expansáo física da Usina Presidente Vargas

23 Graciolli (2007) e Pereira (2007) oferecem mais informações sobre a fragmentação do movimento sindical de Volta Redonda.

24 35\% do total, segundo o APL Metal Mecânico - Relatório de pesquisa - Ano Base - 2008 - SEBRAE. 
(UPV), mas por sugerir a existência de condicionamentos estruturais que por décadas vêm cercando e inviabilizando os esforços de autonomia do município. A discussão procurou indicar a existência de limitaçôes estruturais definidas pelo tipo de arranjo sociopolítico constituído no território e concluiu tratar-se de uma inverdade a argumentaçáo segundo a qual Volta Redonda perdeu por completo sua condiçáo de company town, na transiçáo da década de 1960 para a de 1970. As evidências empíricas somadas a uma releitura atenta dos pressupostos que orientaram o empreendimento do Estado brasileiro levam à conclusáo de que aspectos originais fundamentais, como a imersão dos conflitos sociais na lógica espacial e a permanente submissáo de setores (poder público e o empresariado) à visáo de mundo da Companhia, explicam o enraizamento da sua dominaçáo no território.

A interpretaçáo clássica sugere que a condiçáo de company town foi superada no final da década de 1960 por conta do abandono de um conjunto de açóes tipicamente paternalistas, com maior destaque para a fracassada política habitacional da CSN. Não obstante, a discussão aqui empreendida se propôs a apostar na manutenção do status de cidade-companhia justamente porque dois princípios fundamentais se mantiveram preservados: a perspectiva de mudança cultural executada através da política do "desnudamento" e da ação civilizatória pela "instituiçáo industrial-total" comprometida com a conformaçáo de um novo perfil de trabalhador; e a manipulaçáa intencional do landscape para fins de hierarquização/controle do espaço social. Objetivamente falando, processos como a privatizaçáo tiveram efeitos apenas pontuais sobre o desenvolvimento da regiáo, não se transfigurando em uma revitalização do espaço socioeconômico. E, em geral, a leitura ideologizada predominante tendeu a enfatizar os efeitos perversos desse processo sobre o conjunto de trabalhadores, ao passo que contribuiu para obscurecer fatores como a agressiva atuaçáo do Estado brasileiro como agente capitalista responsável, já no final da década de 1970, pela intensa exploração e precarização da máo de obra no interior da Usina Presidente Vargas, aspecto cuja reflexáo ultrapassa as finalidades analíticas mais imediatas do presente artigo.

\section{Referências}

BASTOS, H. A conquista siderúrgica no Brasil. São Paulo: Livraria Martins Editora, 1957. 
BEDÊ, E. D. A. T. Pedagogia do mundo do trabalho na Companhia Siderúrgica Nacional: americanismo, compromisso fordista e a formaçáo da classe operária em Volta Redonda. 2007. Tese (Doutorado em Educaçáo) - Universidade Federal Fluminense, Niterói, 2007.

BOURDIEU, P. O poder simbólico. Rio de Janeiro: Bertrand Brasil, 2001.

COWIE, J.; HEATHCOTT, J. The meanings of deindustrialization. In: COWIE, Jefferson; HEATHCOTT, Joseph (Org.). Beyond the ruins: the meanings of deindustrialization. Ithaca: Cornell University Press, 2003. p. 1-15.

DIAS, S. de O. M. Dentro da usina mas fora da "família": trabalhadores e terceirização na Companhia Siderúrgica Nacional (CSN). 2010. Dissertaçáo (Mestrado em Sociologia) Universidade Federal do Rio de Janeiro, Rio de Janeiro, 2010.

DINIUS, O. Brazil's steel city: developmentalism, strategic power and industrial relations in Volta Redonda, 1941-1964. Stanford: Stanford University Press, 2011.

DULCI, J. A. Reestruturaçáo produtiva e mercado de trabalho no Vale do Paraíba fluminense: regiāo ganhadora ou perdedora? 2008. Dissertação (Mestrado em Ciências Estatísticas) - Escola Nacional de Ciências Estatísticas, Rio de Janeiro, 2008.

EGALON, J. R. Volta Redonda como área de segurança nacional: o abandono da política de direitos sociais (1973-1985). 2002. Dissertaçáo (Mestrado em História) - Programa de Mestrado em História, Universidade Severino Sombra, Vassouras. 2002.

ENGELS, F. A situaçáo da classe trabalhadora na Inglaterra. São Paulo: Boitempo, 2010.

EX-PRESIDENTE da CSN. Entrevista: 13 nov. 2011.

FOCO REGIONAL. Sul Fluminense, ano 3, ed. 128, 15 a 21 set. 2003.

FOUCAULT, M. Vigiar e punir: história da violência nas prisões. Petrópolis: Vozes, 1997.

GOFFMAN, E. Manicômios, prisóes e conventos. Sáo Paulo: Perspectiva, 1974.

GRACIOLLI, E. J. Privatizaçáo da CSN: da luta de classes à parceria. São Paulo: Expressão Popular, 2007.

. Um caldeiráo chamado CSN: resistência operária e violência militar na greve em 1988.

2. ed. rev. e ampl. Uberlândia: EDUFU, 2009.

HARVEY, D. A produçáo capitalista do espaço. Sáo Paulo: Annablume, 2005.

HEROD, A. Social engineering through spatial engineering: company towns and the geographical imagination. In: DINIUS, O. J.; VERGARA, A. (Org.). Company towns in the Americas. Athens: The University of Georgia Press, 2011. 
JORNAL DO BRASIL. Rio de Janeiro, edição de 1979.

LIMA, R. J. da C . A “reinvençáo” de uma cidade industrial: Volta Redonda e a pós-privatização da Companhia Siderúrgica Nacional (CSN). 2010. Tese (Doutorado em Sociologia) - Universidade Federal do Rio de Janeiro, Rio de Janeiro, 2010a.

Novas e velhas questốes: revisando a historiografia sobre Volta Redonda (RJ). História Unisinos, Sáo Leopoldo, v. 14, p. 77-87, jan./abr. 2010 b.

LIMA NETTO, R. P. de. A volta por cima: a história da salvaçáo da CSN - Companhia Siderúrgica Nacional, símbolo da industrialização brasileira. Rio de Janeiro: Record, 1993.

LOCKE, R. Remaking the Italian economy. New York: Cornell University, 1995.

LOPES, A. A aventura da forma: urbanismo e utopia em Volta Redonda. Rio de Janeiro: E-Papers, 2003.

LOPES, J. S. L. A tecelagem dos conflitos de classe na "Cidade das Chaminés". São Paulo: Marco Zero; UNB MCT/ CNPq, 1988.

MANGABEIRA, W. Dilemas do novo sindicalismo: democracia e política em Volta Redonda. Rio de Janeiro: Relume Dumará; ANPOCS, 1993.

MARKUSEN, A. Áreas de atraçáo de investimentos em um espaço econômico cambiante: uma tipologia dos distritos industriais. Revista Nova Economia, Belo Horizonte, v. 5, n. 2, p. 9-44, 1995.

MINAYO, M. C. de S. De ferro e flexíveis: marcas do estado empresário e da privatizaçáo na subjetividade operária. Rio de Janeiro: Garamond, 2004.

MONTEIRO, G. T. M. Sindicato dos metalúrgicos de Volta Redonda: 50 anos brasileiros. Rio de Janeiro: FSB Comunicaçóes, 1995.

MOREIRA, R. da L. CSN: um sonho feito de aço e ousadia. Rio de Janeiro: Centro de Pesquisa e Documentação de História Contemporânea do Brasil/Fundação Getúlio Vargas, 2000.

MOREL, R. A ferro e fogo: construçăo e crise da "família siderúrgica": o caso de Volta Redonda (1941-1968). 1989. Tese (Doutorado em Sociologia) - Universidade de Sáo Paulo, São Paulo, 1989.

. História incorporada e identidade coletiva entre trabalhadores aposentados da Companhia Siderúrgica Nacional. In: ABREU, A. R. P.; PESSANHA, E. G. F. (Org.). O trabalhador carioca: estudos sobre trabalhadores urbanos do Rio de Janeiro. Rio de Janeiro: JC Editora, 1995. 
O BRILHO do aço. Revista Exame, 11 jul. 2001. Disponível em: <http://exame.abril.com.br/ revista-exame/edicoes/0744/noticias/o-brilho-do-aco-m0047710>.

O GLOBO. Rio de Janeiro, 8 maio 1983.

PEREIRA, S. E. M. Sindicalismo e privatizaçáo: o caso da Companhia Siderúrgica Nacional. 2007. Tese (Doutorado em Sociologia) - Universidade Federal do Rio de Janeiro, Rio de Janeiro, 2007.

PIQUET, R. Cidade-empresa: presença na paisagem urbana brasileira. Rio de Janeiro: Zahar, 1998.

RADY, D. E. Volta Redonda: a steel mill comes to a brazilian coffee plantation. Washington DC: Industrial Entrepreneurship in a Developing Economy, 1973.

RAMALHO, J. R. Flexibilidade e crise do emprego industrial: sindicatos, regióes e novas açóes empresariais. Sociologias (UFRGS. Impresso), Porto Alegre, v. 12, p. 252-284, set./dez. 2010.

Fórum Demissão Zero: crise e ação coletiva no sul fluminense. In: RAMALHO, J. R.; FORTES, A. (Org.). Desenvolvimento, trabalho e cidadania. Rio de Janeiro: Sete Letras, 2012. REPRESENTANTE da CSN. Entrevista: 10 ago. 2012.

SEBRAE - Serviço Brasileiro de Apoio às Pequenas e Médias Empresas. O APL metal mecânico. Relatório de Pesquisa, ano-base 2008.

SOUZA, C. V. C. Pelo espaço da cidade: aspectos da vida e do conflito urbano em Volta Redonda. 1992. Dissertaçáo (Mestrado em Planejamento Urbano e Regional) - Universidade Federal do Rio de Janeiro, Rio de Janeiro, 1992.

VALOR ECONÔMICO. São Paulo, 11 mar. 2013.

VÉDRINE, C. From paternalist town to the city of pleasure: the case of Clermont-Ferrand and the Michelin company. In: WISERD CONFERENCE: CHANGING WALES: SOCIAL, ECONOMIC AND POLITICAL PERSPECTIVES, 2011, Swansea.

VOLTA REDONDA (Município). Lei municipal no 1411 , de $1^{\circ}$ de fevereiro de 1977. Câmara Municipal de Volta Redonda.

Data de recebimento: 09.01 .2013

Data de aprovaçáo: 16.09.2013 


\section{CSN and Volta Redonda: a historical relationship of dependency and control}

\section{Abstract}

As according to the morphological characterization of the space which comprises Volta Redonda $(\mathrm{RJ})$, this paper analyses the inter-relationship of dependency and control created by the presence and performance of the Companhia Siderúrgica Nacional (CSN) in this city. It is understood that, in the last several decades, the Company controlled (imposed over) the territory and repressed developmental possibilities excepting those related to steel production - until recently, its core business. This paper initiates with the study of the socio-anthropological phenomena of a company town and suggests that Volta Redonda preserves those same fundamental characteristics of this model of control and hierarchy of its space generally identified in the configuration of its urban landscape. With this, we seek to understand the resulting implications of the mono-industrial design and the technical and organizational changes of CSN as respective of the economic geography of the city.

Keywords: Company town; CSN; Economic geography; Steel industry; Volta Redonda. 